This item was submitted to Loughborough's Research Repository by the author.

Items in Figshare are protected by copyright, with all rights reserved, unless otherwise indicated.

\title{
The accuracy and reliability of traditional surface flow type mapping: Is it time for a new method of characterizing physical river habitat?
}

\section{PLEASE CITE THE PUBLISHED VERSION}

https://doi.org/10.1002/rra.3047

\section{PUBLISHER}

(C) John Wiley \& Sons, Ltd.

\section{VERSION}

AM (Accepted Manuscript)

\section{PUBLISHER STATEMENT}

This work is made available according to the conditions of the Creative Commons Attribution-NonCommercialNoDerivatives 4.0 International (CC BY-NC-ND 4.0) licence. Full details of this licence are available at: https://creativecommons.org/licenses/by-nc-nd/4.0/

\section{LICENCE}

CC BY-NC-ND 4.0

\section{REPOSITORY RECORD}

Woodget, Amy, F. Visser, lan P. Maddock, and Patrice Carbonneau. 2019. "The Accuracy and Reliability of Traditional Surface Flow Type Mapping: Is It Time for a New Method of Characterizing Physical River Habitat?". figshare. https://hdl.handle.net/2134/37181. 


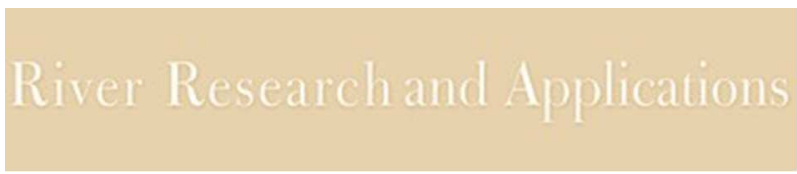

\section{The accuracy and reliability of traditional surface flow type mapping: Is it time for a new method of characterising physical river habitat?}

\begin{tabular}{|r|l|}
\hline Journal: & River Research and Applications \\
\hline Manuscript ID & RRA-15-0149.R2 \\
\hline Wiley - Manuscript type: & Research Article \\
\hline Date Submitted by the Author: & n/a \\
\hline Complete List of Authors: & $\begin{array}{l}\text { Woodget, Amy; University of Worcester, Institute of Science and } \\
\text { Environment } \\
\text { Visser, Fleur; University of Worcester, Institute of Science and } \\
\text { Environment } \\
\text { Maddock, Ian; University of Worcester, Institute of Science and } \\
\text { Environment } \\
\text { Carbonneau, Patrice; Durham University, Department of Geography }\end{array}$ \\
\hline Keywords: & $\begin{array}{l}\text { surface flow type, small unmanned aerial system, sUAS, structure from } \\
\text { motion, hydraulic habitat, river, remote sensing, topography }\end{array}$ \\
\hline
\end{tabular}


The accuracy and reliability of traditional surface flow type mapping: Is it time for a new method of characterising physical river habitat?

\author{
Woodget, A.S., Visser, F., Maddock, I.P. and Carbonneau, P.E.
}

\begin{abstract}
Surface flow types (SFT) are advocated as ecologically relevant hydraulic units, often mapped visually from the bankside to characterise rapidly the physical habitat of rivers. SFT mapping is simple, non-invasive and cost-efficient. However, it is also qualitative, subjective and plagued by difficulties in recording accurately the spatial extent of SFT units. Quantitative validation of the underlying physical habitat parameters is often lacking, and does not consistently differentiate between SFTs. Here, we investigate explicitly the accuracy, reliability and statistical separability of traditionally mapped SFTs as indicators of physical habitat, using independent, hydraulic and topographic data collected during three surveys of a c. $50 \mathrm{~m}$ reach of the River Arrow, Warwickshire, England. We also explore the potential of a novel remote sensing approach, comprising a small unmanned aerial system (sUAS) and Structure-from-Motion photogrammetry (SfM), as an alternative method of physical habitat characterisation. Our key findings indicate that SFT mapping accuracy is highly variable, with overall mapping accuracy not exceeding $74 \%$. Results from analysis of similarity (ANOSIM) tests found that strong differences did not exist between all SFT pairs. This leads us to question the suitability of SFTs for characterising physical habitat for river science and management applications. In contrast, the sUAS-SfM approach provided high resolution, spatially continuous, spatially explicit, quantitative measurements of water depth and point cloud roughness at the microscale (spatial scales $\leq 1 \mathrm{~m}$ ). Such data are acquired rapidly, inexpensively, and provide new opportunities for examining the heterogeneity of physical habitat over a range of spatial and temporal scales. Whilst continued refinement of the sUAS-SfM approach is required, we propose that this method offers an opportunity to move away from broad, mesoscale classifications of physical habitat (spatial scales 10$100 \mathrm{~m}$ ), and towards continuous, quantitative measurements of the continuum of hydraulic and geomorphic conditions which actually exists at the microscale.
\end{abstract}

\title{
Introduction
}

Surface flow types (SFTs) are visible water surface patterns within river systems often used as a proxy for biotopes or in-stream hydraulic habitat units (Padmore, 1998; Newson and Newson, 2000). The spatial distribution of SFTs is thought to be determined by local variations in morpho-hydraulic conditions, including topography, substrate size, water depth and flow velocity (Padmore, 1998; Wadeson and Rowntree, 1998; Newson and Newson, 2000; Dyer and Thoms, 2006; Reid and Thoms, 2009). Various classification schemes have been proposed to define SFTs or their equivalent biotopes (e.g. Bisson et al., 1982; Wadeson, 1994; Montgomery and Buffington, 1997; Raven et al., 1997; Newson and Newson, 2000) and their visual identification has been advocated as an effective means of characterising the physical river habitat template at the mesoscale (Reid and Thoms, 2008; Harvey and Clifford, 2009; Zavadil et al., 2012). Furthermore, the view that SFTs represent hydraulically meaningful and consistent units, and the strong influence of hydraulic conditions on instream biota (Reid and Thoms, 2008; Hill et al., 2013), has resulted in a growing popularity within the field of ecohydraulics for conducting rapid habitat assessments using SFTs (Newson and Newson, 2000; Dyer and Thoms, 2006; Reid and Thoms 2008). As well as characterising hydraulic diversity, SFTs are also thought to be indicative of geomorphic diversity (Zavadil et al., 2012). 
Traditionally, SFT mapping is carried out by visual assessment from the bankside. For example, the UK's River Habitat Survey (RHS) records the dominant SFT (Table 1) across $1 \mathrm{~m}$ wide cross sections at ten spot check locations every $50 \mathrm{~m}$ along a $500 \mathrm{~m}$ reach (Environment Agency, 2003). Other approaches have recorded the relative proportions of SFTs within 50m cells (Dyer and Thoms, 2006), estimated the spatial extent of SFTs (Hill et al., 2013), and recorded SFTs at specific distances along channel cross sections (Wadeson and Rowntree, 1998). Such approaches are rapid, non-invasive and advocated to provide a valid alternative to the labour intensive, time consuming point measurements of bed elevations, water depths and velocities for characterising hydraulic and geomorphic diversity (Reid and Thoms, 2008). However, whilst cost effective and easy to conduct, these visual SFT mapping approaches are qualitative and are usually unaccompanied by quantitative validation. They are subjective, affected by user bias and plagued by difficulties in determining the precise spatial extent of different SFT units due to the indistinct nature of SFT boundaries and the difficulty of producing accurate maps from an oblique, bankside viewpoint (Reid and Thoms, 2009; Milan et al., 2010). Efforts to characterise the hydraulic and geomorphic nature of SFTs (using measures such as flow velocity, Froude number or cross-sectional geometry) find that SFTs are not always statistically separable, and that significant overlaps in conditions between SFTs are often present (Wadeson, 1994; Newson et al., 1998; Wadeson and Rowntree, 1998; Clifford et al., 2006; Moir and Pasternack, 2008; Reid and Thoms, 2008; Gosselin et al., 2012; Zavadil et al., 2012). As a result, can we be certain of the accuracy and reliability of traditional SFT mapping as a universal approach for characterising physical habitat within rivers?

Remote sensing surveys provide an alternative means of SFT mapping (Newson and Newson, 2000), which offer the opportunity for permanent, digital, spatially continuous and spatially explicit datasets, against which change over time can be assessed and other types of spatial analysis performed. Historically, the expense of acquiring remotely sensed data has prohibited its widespread use for SFT mapping. However, some research has demonstrated the use of multispectral imagery (Hardy et al., 1994; Winterbottom and Gilvear 1997; Wright et al., 2000; Reid and Thoms, 2009), hyperspectral imagery (Legleiter et al., 2002; Marcus, 2002; Marcus et al., 2003) and measures of roughness derived from terrestrial laser scanning (TLS) point clouds (Large and Heritage, 2007; Milan et al., 2010) for mapping SFTs (and/or in-stream habitat) over a range of scales. Most of these studies report good agreement between SFTs mapped from the remote sensing and using the traditional bankside approach, and in some cases it is argued that the remote mapping might actually provide a more accurate and precise representation of the spatial arrangement of SFTs (Hardy et al., 1994; Marcus, 2002; Reid and Thoms, 2009; Bentley et al., 2016). Unfortunately, quantitative and independent validation data are not usually available to assess such findings and therefore we remain largely uncertain of the accuracy and reliability of traditional bankside SFT mapping or that based on remotely sensed data.

Our aims within this paper are twofold:

(1) To use a range of independent, spatially explicit, microscale quantitative measurements to investigate the accuracy and reliability of traditionally mapped SFTs as indicators of physical habitat conditions.

(2) To explore the potential of a novel remote sensing technique for providing an alternative approach to SFT mapping for characterising physical habitat.

To achieve our first aim, we acquire quantitative validation data; (i) in the field, using established methods and; (ii) from remotely sensed imagery acquired using a small unmanned 
aerial system (sUAS), otherwise known as a drone, RPAS (remotely piloted aircraft system) or UAV (unmanned aerial vehicle). In recent years sUAS, combined with structure-frommotion photogrammetry (SfM), have provided a new remote sensing tool capable of rapid and flexible acquisition of hyperspatial resolution imagery $(<10 \mathrm{~cm})$ and the production of high accuracy, quantitative, topographic data (e.g. Harwin and Lucieer, 2012). This sUAS$\mathrm{SfM}$ approach has seen a huge surge in popularity for a wide range of environmental science and monitoring applications, especially for smaller sites, which would otherwise be impossible or too costly to survey using established remote sensing approaches. Quantification of some river habitat parameters has already been demonstrated (e.g. Reid and Thoms, 2009; Fonstad et al., 2013; Tamminga et al., 2015; Woodget et al., 2015), and we anticipate that the sUAS-SfM toolkit now offers new possibilities for high resolution, spatially explicit and quantitative assessments of the accuracy and reliability of traditional SFT mapping. For our second aim, we take this assessment a step further to explore whether the sUAS-SfM approach itself offers an alternative means of characterising physical habitat. Our objectives are:

1. To compare quantitatively the traditional SFT mapping against;

a. An independent SFT ground truth dataset collected in the field, and;

b. $\quad$ SFT mapping conducted from hyperspatial resolution sUAS-SfM imagery (which itself is then compared to the ground truth data).

2. To test statistically whether SFTs mapped traditionally from the bankside can be differentiated reliably based on quantitative data derived from;

a. Water depth and flow velocity data acquired in the field, and;

b. Hyperspatial resolution sUAS-SfM imagery and topography data.

3. To quantify physical habitat parameters using sUAS-SfM derived topography data.

\section{Site Location}

We conducted this research on a $50 \mathrm{~m}$ reach of the River Arrow, a small (5-12m wide), lowland river (catchment area $93.72 \mathrm{~km}^{2}$ ) located near Studley, Warwickshire, UK. The site provides a diverse range of SFTs at the mesoscale, has a wadeable channel $(<0.7 \mathrm{~m}$ deep $)$, is safe for sUAS flying and was easily accessible for repeat surveying. We collected three repeat surveys of the site to allow comparison of results obtained under differing conditions.

The reach of interest forms a meandering, pool-riffle system, with steep banks and active erosion on the outer meander bends. Point bars are present, with gravels and cobbles also accumulating around the margins of vegetated islands. There are some submerged macrophytes, and in places the channel is obscured by overhanging vegetation. The channel bed is composed predominantly of cobbles with some patches of gravel, sands and silt substrates. Flow level is highly responsive to rainfall events. National River Flow Archive data for the time of our surveys reports a discharge range between 0.94 (August) and 1.72 cumecs (May) from the nearest gauging station, which is located further downstream at Broom (catchment area $\left.319 \mathrm{~km}^{2}\right)(\mathrm{CEH}, 2015)$. These discharge values equate to flow exceedance percentages of Q85 to Q48 respectively, based on long term (1957-2013) flow data acquired at this gauging station (CEH, 2015).

\section{Methods}

Traditional SFT Mapping

During each of our three field campaigns (May, June and August 2013), we mapped the spatial extents of SFTs from the bankside using the RHS classification (Table 1) and hardcopy base maps at a scale of 1:150 (May) or 1:200 (June/August). We subsequently 
scanned and georeferenced our annotated maps, then digitised the mapped SFT units using ArcGIS v. 10 (ESRI Inc.).

\section{Independent Ground Truthing}

During each campaign, we also conducted an independent or 'ground truth' SFT survey in the field by assessing SFTs at 60-100 point locations, the positions of which were recorded using a Trimble R8 differential global positioning system (dGPS) or Leica Builder 500 total station (TS) by a team of two people. We viewed the SFTs from different angles, rather than solely from a bankside or in-channel location, and at each point measured water depth $( \pm 1 \mathrm{~cm})$ and mean column velocity $(\mathrm{m} / \mathrm{s})$ at 0.6 depth using a Valeport EM801 electromagnetic flow meter.

\section{sUAS-SfM Survey and Image Processing}

Prior to our sUAS surveys, we characterised the camera geometry to establish the flying height necessary to obtain c. $1 \mathrm{~cm}$ resolution imagery using the Panasonic Lumix DMC-LX3 (10.1MP) camera attached to our Draganflyer X6, a small and lightweight $(1 \mathrm{~kg})$ rotarywinged sUAS. We also distributed c. 20 ground control points (GCPs) throughout the site prior to flying and surveyed their positions using the dGPS or TS. Our GCPs comprise markers constructed from $20 \mathrm{~cm}$ x $20 \mathrm{~cm}$ squares of black polyvinyl chloride (PVC) plastic sheeting and white spray paint. We collected imagery from an altitude of $25-30 \mathrm{~m}$ and with a high level of overlap (typically 60-80\%) to ensure successful SfM processing. Previous use of this imagery for quantifying submerged fluvial topography is presented in Woodget et al., (2015).

Following the field campaigns, we assessed sUAS image quality to remove those affected by blur. We processed the remaining images using a SfM workflow within Agisoft's PhotoScan Pro software (v. 0.9.1.1714). Outputs included a hyperspatial resolution orthophoto mosaic, a digital elevation model (DEM) and a dense point cloud. The latter comprises a cloud of points arranged in $3 \mathrm{D}$ space, each of which has XYZ co-ordinates describing its location within a 3D model of the scene. Point clouds created by the SfM process are similar to those produced by laser scanning and permit different ways of examining topographic surfaces (e.g. Rychov et al., 2012).

We used the sUAS-SfM orthophoto mosaics to map SFTs as polygons within ArcGIS at a scale of 1:50. We conducted this manually (rather than using image classification procedures) based on the visual properties of the water surface. We derived quantitative data from the sUAS-SfM process in the form of refraction corrected (RC) water depth and point cloud roughness, both as raster datasets. Woodget et al., (2015) provides further detail concerning water depth estimation and the required refraction correction procedure, as initially proposed by Westaway et al., (2000). We used the freeware package CloudCompare (GirardeauMontaut, 2014) to compute the roughness (i.e. fine scale variation in elevation) of the point cloud. In theory, greater roughness in the point cloud may result from greater water surface roughness, greater water depths and larger submerged grain sizes. Therefore, variations in point cloud roughness may be indicative of variations in physical habitat conditions. Roughness is defined as the distance between each point and the least squares best fitting plane computed on its nearest neighbours within a sphere of a given size. We chose a sphere radius of $0.2 \mathrm{~m}$ based on a priori knowledge that the typical size of SFT features at this site does not exceed $0.4 \mathrm{~m}$. Per-point roughness data were rasterised at $5 \mathrm{~cm}$ resolution.

Analysis 
Objective 1.a) To compare quantitatively the spatial positioning of the traditional SFT mapping against the ground truth data, we extracted the bankside SFT classifications from each dataset at the location of each ground truth point and compiled the data into a confusion matrix. These matrices are often employed for assessing the accuracy of automated or manual image classifications (Lillesand and Kiefer, 2000) by comparing their performance against datasets of true or known values. We computed the overall accuracy, user's accuracy and kappa co-efficient from the confusion matrix to assess the performance of the traditional SFT mapping. Definitions of these accuracy measures are provided in Table 2.

Objective 1.b) We also compared quantitatively the traditional SFT mapping against the SFT mapping conducted on the high resolution sUAS-SfM orthophoto. SFT classes were extracted from both mapping datasets at $0.5 \mathrm{~m}$ spaced grid points in ArcGIS. Here, we sought not to use the sUAS-SfM SFT mapping as ground truth, but instead we compiled the resulting data to compare levels of agreement between these two mapping approaches. For completeness, we also compared quantitatively the spatial positioning of the sUAS-SfM SFT mapping against the ground truth data, in the same way as described for the traditional SFT mapping in objective 1a.

Objective 2) To test whether the traditionally mapped SFTs were statistically separable from each other, analysis of similarity (ANOSIM) tests were performed. We conducted two ANOSIM tests for each survey, using different combinations of spatially explicit, quantitative input data that provide an indication of topographic and hydraulic diversity;

- Test A: Water depth and flow velocity data acquired in the field.

- Test B: Hyperspatial resolution image and topography data in the form of RC water depth and point cloud roughness, obtained readily from the sUAS-SfM data.

We assessed SFT separability for each survey and scenario using PRIMER 6 (PRIMER-E Ltd, v. 6.1.13) and $\alpha=0.05$. Data were checked for normality and standardised by subtracting the mean and dividing by the standard deviation. A resemblance matrix was generated for each test, which details the differences between all data points in Euclidean distances. The SFT classifications for each point were added and the resemblance matrix used to conduct a one-way ANOSIM test. ANOSIM tests are based on the corresponding rank similarities between data points in the resemblance matrix, and not on actual Euclidean distances (Clarke and Warwick, 2001). The outputs included a global $R$ value (comparative measure of the degree of difference between all SFTs), a global significance or $p$ value, and a series of $R$ statistic and $p$ values for each pair-wise comparison of SFTs.

Objective 3) To characterise the physical habitat conditions for each survey using the sUASSfM approach, we produced maps, distribution profiles and descriptive statistics of RC water depth and point cloud roughness. Whilst other factors also contribute to the physical habitat, such as grain size and flow velocity, we did not attempt to quantify these parameters in this instance.

\section{Results and Analyses \\ Objective 1.a) Comparison with ground truth}

A quantitative comparison of the traditionally mapped SFTs with the independent ground truth data is provided in Table 3 (columns headed 'TB'). The overall results are variable, as indicated by the range in overall accuracy and kappa coefficient, with overall accuracy not exceeding $74 \%$ for any of the three surveys. The accuracy of mapping individual SFTs is highly variable across different SFTs and between different surveys. This is particularly notable within the August survey where user's accuracies range from $0 \%$ to $100 \%$. Areas of 
smooth flow and unbroken standing waves, which typically occupy the larger proportions of the channel, give user's accuracies consistently greater than $64 \%$ and $58 \%$ respectively, although again there is variability between surveys. Very poor user's accuracies $(<30 \%)$ are observed for areas of upwelling during the May and August surveys. This is possibly because areas of upwelling occupy a very small proportion of the channel during these surveys. As a result, they may be more susceptible to spatial misalignments or misclassifications relating to transition zones between SFTs. Overall, comparison against independent ground truth data suggests that we have not been able to map the positions and types of surface flow with a consistently high accuracy using the traditional approach of visual assessment from the bankside.

\section{Objective 1.b) Comparison with sUAS-SfM SFT mapping}

Figure 1 provides examples of SFT mapping conducted in the traditional way from the bankside (top), and from the sUAS-SfM imagery (bottom). A quantitative comparison of these two approaches is provided for all surveys in Figure 2, where percentage agreement indicates the percentage of points mapped as a given SFT by the traditional survey, which are also mapped as this SFT by the sUAS-SfM survey. These data indicate that the highest levels of agreement and greatest levels of between-survey consistency are found for the smooth SFT (76-87\%). The range in agreement across SFTs within a single survey is lowest for the June dataset (54-80\%). Otherwise however, levels of agreement across different SFTs and between different surveys are highly variable. For example, percentage agreements range $0-65 \%$ for no perceptible flow and $18-100 \%$ for upwelling across the three surveys. Within the August survey, percentage agreement for individual SFTs ranges from $0 \%$ (no perceptible flow) to $100 \%$ (upwelling). These results may be due, in part, to the low number of comparison points falling within some of the smaller SFTs (e.g. upwelling, Figure 1). Overall, the results suggest that the traditional mapping is not able to match reliably the position and type of SFTs as mapped from hyperspatial resolution imagery across the different surveys. However, a quantitative assessment of the sUAS-SfM SFT mapping itself against the ground truth data finds that it too is incapable of producing consistently high accuracies, across the three surveys and across the different SFTs (Table 3).

\section{Objective 2) Statistical separability}

The global $\mathrm{R}$ values and pair-wise comparisons for all surveys and scenarios are presented in Table 4. Whilst global $\mathrm{R}$ values are higher for Test $\mathrm{A}$, they are notably low across both tests $(<0.32)$. This indicates that despite the use of objective, spatially explicit and quantitative data to define SFTs, the differences between these SFTs are not strong for any of the three surveys or under either of the two ANOSIM test scenarios. Results for all surveys and scenarios are found to be statistically significant at $\alpha=0.05$.

With regards to the pair-wise comparisons, the most consistent separation is typically observed for 'smooth-upwelling' and 'unbroken standing waves-upwelling' for both Tests A and B. Test A also produces fairly consistent high R values for SFT pairs 'unbroken standing waves-no perceptible flow' and 'rippled-upwelling', which are always statistically significant. However, low or inconsistent $\mathrm{R}$ values are observed in most other pair-wise comparisons. Overall, this suggests that differentiation of all SFTs cannot be conducted reliably with the use of quantitative data from either of the two test scenarios.

Objective 3) Quantifying physical habitat using sUAS-SfM data

Example high resolution maps from the May survey and distribution profiles for all surveys of RC depth and point cloud roughness are provided in Figures 3 and 4. Descriptive statistics 
are shown in the inset table of Figure 5. We observe a greater mean water depth, range of depths and standard deviation of depth during the June survey than in May or August. In contrast, roughness statistics are broadly similar across all three surveys, with the August survey showing slightly higher mean, minimum, maximum and range values. Percentiles of the RC depth distribution were compared with percentiles obtained from the roughness distribution (Figure 5). Excellent linear relationships are evident $\left(\mathrm{R}^{2}>0.97, \mathrm{n}=101, \mathrm{p}<\right.$ 0.01 ), with the slope of the trend line for the June survey being clearly different from the other two surveys due to the presence of greater water depths overall, and typically lower roughness values than observed for the equivalent depths of the May and August surveys.

\section{Discussion}

Our work has demonstrated that accurate, reliable, objective identification of SFTs is not possible, even with the use of quantitative hydraulic data or hyperspatial image and topography data. This raises important questions about the suitability of SFTs as a physical quantity in process-based science and evidence-based river management. In theory, SFT mapping provides a framework for classifying river habitat, in which the detail of the microscale is summarised, with a view to enabling larger scale habitat assessments for river science and management (Newson and Newson, 2000). The successful application of this approach is thus reliant on the assumption that SFT mapping provides an accurate and consistent overview of the detailed hydraulic and geomorphic conditions (i.e. elements of the physical habitat), or at least represents the diversity of such conditions within a mesoscale length of channel. Our study has assessed a traditional SFT mapping approach against independent validation data and found that in practice, the overall classification accuracy of SFT mapping never exceeds $74 \%$ and can be as low as $57 \%$. Furthermore and crucially, SFT classification mapping accuracy is highly inconsistent between SFTs and surveys, and is not improved by mapping SFTs onto the high resolution sUAS-SfM imagery. Similar results are found by other quantitative studies (e.g. Marcus, 2002; Marcus et al., 2003; Gosselin et al., 2012; Bentley et al., 2016).

The statistical separability of SFT pairs using quantitative variables has also been tested within this paper, and elsewhere. Some results provide quantitative evidence of the separability of specific SFT pairs using hydraulic or geomorphic data (e.g. Reid and Thoms, 2008; Newson and Newson, 2000; Zavadil et al., 2012), yet no single study has been able to demonstrate statistical separability of all SFT pairs, leading many to suggest that the amalgamation of certain units is necessary (Wadeson and Rowntree, 1998; Reid and Thoms, 2008; Zavadil et al., 2012). Additionally, wider results lack consistency between studies conducted on different river systems and under differing flow conditions (Gosselin et al., 2012), lending further support to the notion that traditional SFT mapping is not reliable as a universal method for characterising hydraulic and geomorphic conditions. This may in part relate to field measurement errors and/or visual misclassifications of SFTs resulting from similar surface topography signatures and varying scene illumination conditions, such as the commonly recognised difficulty in distinguishing between rippled flow and unbroken standing waves (Padmore, 1998; Milan et al., 2010). However, we anticipate that the observed lack of reliability also results from within-SFT hydraulic and geomorphic heterogeneity and genuine overlaps in conditions between SFTs, which are reflected within our microscale, quantitative validation data. This has been observed elsewhere in the form of transition zones and as small patches of hydraulic conditions (sometimes expressed as different surface patterns) typically associated with one SFT being found within another (e.g. Wadeson, 1994; Wadeson and Rowntree, 1998; Marcus 2002; Marcus et al., 2003; Legleiter et al., 2002; Legleiter and Goodchild, 2005; Milan et al., 2010; Wallis et al., 2010; Bentley et 
al., 2016). For example, the work of Wallis et al., (2010), on an adjacent reach of the same River Arrow we study here, found that transition zones between hydraulic patches occupied a significant proportion of the channel extent (33-38\%) over a range of discharges (Q13 to Q70). Using remote sensing approaches, the works of Marcus (2002) and Marcus et al., (2003) note the presence of small, pixel-scale patches on classifications of instream habitat produced from $1 \mathrm{~m}$ resolution hyperspectral imagery. They argue that this heterogeneity represents real differences in physical habitat, which are often returned as false misclassifications due to the coarser scale validation units mapped in the field. Harvey and Clifford (2009) explored the microscale hydrodynamics of physical biotopes and found that hydraulic heterogeneity not only existed within biotopes but that the magnitude of this heterogeneity varied between biotopes. They also highlighted the importance of this microscale hydraulic diversity (such as refugia and other marginal features) as having a more direct influence on the survival of in-stream biota than hydraulic variability at the mesoscale. Such findings underline the importance of scale in assessments of physical river habitat, and further reinforce the idea that traditional SFT mapping at the mesoscale greatly simplifies the continuum of microscale hydraulic and geomorphic conditions that are actually present (Legleiter et al., 2002; Clifford et al., 2006). Whilst this is a known characteristic of classification schemes in general, the wider findings of this paper lead us to question the ongoing use of SFTs for characterising physical river habitat.

We propose that the time has come to move away from broad, mesoscale classification schemes for characterising the hydraulic and geomorphic elements of physical habitat, and towards spatially continuous, spatially explicit, quantitative measurements at the microscale. Initially, the SFT classification scheme was developed from a need for rapid, inexpensive surveys, which did not require the need for specialised knowledge. At that time, "...the 'luxury' of a full hydraulic description of habitat at the microscale..." was not available, and “...must await technological progress" (Newson and Newson, 2000, p. 202). We argue that significant technological advances in sUAS platforms and SfM processing techniques now provide an alternative approach for assessing physical habitat, which is still rapid, inexpensive and becoming increasingly accessible to the non-specialist. Furthermore, sUASSfM approaches are capable of providing the 'luxury' of high resolution, quantitative, spatially continuous and explicit data at the microscale. We have demonstrated the generation of orthophoto and topography data (water depth and point cloud roughness) using this approach. Such data provide new opportunities for examining the detailed heterogeneity of hydraulic and geomorphic conditions, including small and marginal features, which might otherwise be overlooked by broad classification systems. Next, we can examine the ecological importance of this heterogeneity, its spatial significance and dynamics over time, as well as summarise the detail of this information over a range of spatial scales. Why would we continue to infer the characteristics of mesoscale physical habitat units (using traditional SFT mapping), when we are now capable of measuring them quantitatively at the microscale? Of course, the answer to this question will be determined by the specific requirements of the intended application, as well as the availability of resources, time and funds. In our experience, the rapid mobilisation and image acquisition using the Draganflyer X6 means that c. $500 \mathrm{~m}$ lengths of channel can easily be covered within a day's fieldwork with a team of two people. Newer fixed-wing sUAS are capable of even faster acquisitions, resulting from longer battery life and autopilot functions, so that up scaling of this approach to larger reaches is feasible. In comparison to other remote sensing approaches, these are larger areas and much quicker acquisitions than currently possible using equivalent high resolution methods like TLS (e.g. Large and Heritage, 2007; Milan et al., 2010), and significant time and cost savings over the commissioning of multi- or hyper-spectral aerial surveys (e.g. 
Marcus, 2002; Marcus et al., 2003), albeit for smaller spatial areas. Broadly similar platforms to the Draganflyer X6 (acquired in 2010 for c. £29,500) are now available at low cost and can be acquired at the time of writing for around $£ 1,150$ (GBP). In terms of the processing software, Agisoft's PhotoScan Pro can be purchased for \$549/\$3499 (USD) for educational or commercial stand-alone licences respectively.

Whilst we advocate a sUAS-SfM approach for quantifying physical habitat conditions, we note that further testing over a range of different fluvial settings and flow conditions is needed. We also note some important caveats concerning this method. For example, accurate water depth estimation requires clear water, shallow depths, minimal white water and sufficient knowledge of the SfM process to avoid introducing systematic errors. Readers are referred to Woodget et al., (2015) for a more detailed evaluation of the water depth quantification method. In terms of point cloud roughness, whilst we do not observe a direct correlation with hydraulic conditions, our detailed local knowledge of the River Arrow site leads us to suggest that a combination of water surface topography, water depth and submerged grain size are responsible for the observed roughness signature. As such, the maps and distribution profiles of roughness (Figures 3,4,5) provide useful indicators of physical habitat heterogeneity, and future work should explore the ecological significance of these patterns. However, we suspect some factors that do not have a direct influence on physical habitat also influence point cloud roughness, namely sUAS image quality and water clarity. Image quality can be degraded by blurring, caused by poor scene illumination or a lack of platform or sensor stability (de Haas et al., 2014). Blur introduces noise to the point cloud. This results in patches of erroneously high roughness, which may be variable across the scene. Greater water turbidity and depth are likely to reduce water clarity, causing material on the channel bed to become obscured and thus reduce the texture within the sUAS imagery. The SfM process is heavily reliant on texture for accurate point matching. Where texture is lacking, point matching is less successful and either fails completely, or produces a noisy, rough point cloud. Therefore, we anticipate that the sUAS-SfM approach is not appropriate for much deeper and more turbid waters than shown here. Woodget et al., (2015) find success at depths up to $0.7 \mathrm{~m}$, although we have not yet quantified at precisely what depth and turbidity level the method would begin to fail. Fortunately, ongoing research and development means that a reduction of the impact of image quality and water clarity on point cloud roughness may be possible. For example, improvements in sUAS camera gimbals and automated methods for blur removal are already in progress (e.g. Sieberth et al., 2015), and whilst water clarity issues are widely recognised as limiting factors in fluvial remote sensing studies in general (Winterbottom and Gilvear 1997; Gilvear et al., 1995), they might be ameliorated to some extent in future with the use of higher bit depth imagery. We also note that there remain some important physical habitat parameters that we have not quantified using the sUAS-SfM approach within this paper, including cover, flow velocity and grain size. Rapid developments continue to occur in the sUAS-SfM field however (e.g. Rivas Casado et al., 2015; Tamminga et al., 2015; Tauro et al., 2015) and quantification of these parameters is already underway (e.g. Tunnicliffe et al., 2016; Woodget et al., 2016). As such, we believe that the sUAS-SfM approach has great potential, and with further rigorous and quantitative testing, could become the tool of choice for routine and reliable assessments of physical river habitat in future.

\section{Conclusions}

Within this paper, we have investigated the accuracy and reliability of traditional SFT mapping using a range of independent, quantitative data. We have also explored the potential of a novel remote sensing approach as an alternative means of characterising physical habitat 
within a small, shallow, lowland river in the UK. The overall accuracy of SFT mapping was found to be variable across three repeat surveys of the same reach, and did not exceed $74 \%$ on any occasion. The accuracy of mapping specific SFT units was also found to be highly variable between SFTs and different surveys. Analysis of similarity tests provided evidence that the SFTs considered within this study did not have a strong identity and thus could not be reliably differentiated from each other using quantitative hydraulic and geomorphic data. This led us to question the use of traditional SFT mapping as a universal approach for characterising physical habitat accurately and reliably, for both science and management applications. In contrast, a novel remote sensing approach using an unmanned aerial system and structure-from-motion photogrammetric processing was able to provide high resolution, spatially continuous, quantitative data to describe physical habitat at the microscale. Our results suggest that with continued testing and development, this approach holds great potential for becoming a valuable tool for quantification and monitoring of physical river habitat.

\section{Acknowledgements}

This work was conducted as part of a University of Worcester funded $\mathrm{PhD}$ studentship. The fieldwork assistance of James Atkins, Robbie Austrums, Jenni Lodwick, William Woodget and Martin Wilkes was much appreciated. Advice on using PRIMER from Tory Milner is gratefully acknowledged. Our thanks also go to the landowner for his continued kindness and co-operation and two reviewers for helpful comments on an earlier draft.

\section{References}

Bentley, S.G., England, J., Heritage, G., Reid, H., Mould, D. and Bithell, C. (2016) Longreach biotope mapping: Deriving low flow hydraulic habitat from aerial imagery. River Research and Applications, doi: 10.1002/rra.3000

Bisson, P.A., Nielsen, J.L., Palmason, R.A. and Grove, L.E. (1982) A system of naming habitat types in small streams, with examples of habitat utilisation by salmonids during low stream flow. In Armandtrout, N.B. (Eds) Acquisition and Utilisation of Aquatic Habitat Information, Western Division of the American Fisheries Society, Portland, Oregon, p. 6273.

Centre for Ecology and Hydrology (CEH) (2015) Mean Flow Data: River Arrow at Broom. Available online: http://www.ceh.ac.uk/data/nrfa/data/meanflow.html?54007 (accessed 26.05.2015)

Clarke, K.R. and Warwick, R.M. (2001) Change in marine communities: An approach to statistical analysis and interpretation. Second Edition, PRIMER-E Ltd, Plymouth.

Clifford, N.J., Harmar, O.P., Harvey, G. and Petts, G.E. (2006) Physical habitat, ecohydraulics and river design: a review and re-evaluation of some popular concepts and methods. Aquatic Conservation: Marine and Freshwater Ecosystems 16: 389-408.

De Haas, T., Ventra, D., Carbonneau, P. and Kleinhans, M.G. (2014) Debris flow dominance of alluvial fans masked by runoff reworking and weathering. Geomorphology 217: 165-181.

Dyer, F.J. and Thoms, M.C. (2006) Managing river flows for hydraulic diversity: an example of an upland regulated gravel-bed river. River Research and Applications 22: 257-267. 
Environment Agency (2003) River Habitat Survey in Britain and Ireland: Field Survey

Guidance Manual. Available online:

https://www.gov.uk/government/uploads/system/uploads/attachment_data/file/311

579/LIT 1758.pdf (accessed 11.02.2015).

Fonstad, M.A., Dietrich, J.T., Courville, B.C., Jensen, J.L. and Carbonneau, P.E. (2013) Topographic structure from motion: a new development in photogrammetric measurement. Earth Surface Processes and Landforms 38 (4): 421-430.

Gilvear, D.J., Waters, T.M. and Milner, A.M. (1995) Image analysis of aerial photography to quantify changes in channel morphology and instream habitat following placer mining in interior Alaska. Freshwater Biology 34: 389-398.

Girardeau-Montaut, D. (2014) CloudCompare Software v.2.5. Available online: http://www.danielgm.net/cc/ (accessed 05.01.2014).

Gosselin, M.-P., Maddock, I. and Petts, G. (2012) Mesohabitat use by Brown Trout (Salmo trutta) in a small groundwater-dominated stream. River Research and Applications 28: 390401.

Hardy, T.B., Anderson, P.C., Neale, C.M.U., and Stevens, D.K. (1994) Application of multispectral videography for the delineation of riverine depths and mesoscale hydraulic features. In Marston, R.A. and Hasfurther, V.R. (Eds) Effects on Human-Induced Changes on Hydrological Systems, Proceedings of the American Water Resources Association, Jackson Hole, Wyoming, June 1994, p. 445-454.

Harvey, G. and Clifford, N. (2009) Microscale hydrodynamics and coherent flow structures in rivers: Implications for the characterisation of physical habitat. River Research and Applications 25: 160-180.

Harwin, S. and Lucieer, A. (2012) Assessing the accuracy of georeferenced point clouds produced via multi-view stereopsis from unmanned aerial vehicle (UAV) imagery. Remote Sensing 4: 1573-1599.

Hill, G., Maddock, I. and Bickerton, M. (2013) Testing the relationship between surface flow types and benthic macroinvertebrates. In Maddock, I., Harby, A., Kemp, P. and Wood, P. (Eds) Ecohydraulics: An integrated approach Wiley, Chichester.

Large, A. and Heritage, G. (2007) Terrestrial laser scanner based instream habitat quantification using a random field approach. Proceedings of the Remote Sensing and Photogrammetry Society Annual Conference, 11-14 ${ }^{\text {th }}$ September 2007, Newcastle-uponTyne, UK.

Legleiter, C.J., Marcus, W.A. and Lawrence, R.L. (2002) Effects of sensor resolution on mapping in-stream habitats. Photogrammetric Engineering and Remote Sensing 68 (8): 801 807.

Legleiter, C.J. and Goodchild, M.F. (2005) Alternative representations of in-stream habitat: Classification using remote sensing, hydraulic modelling and fuzzy logic. International Journal of Geographical Information Science 19 (1): 29-50. 
Lillesand, T.M. and Kiefer, R.W. (2000) Remote sensing and image interpretation $4^{\text {th }}$ Edition Wiley, New York.

Liu, J.G. and Mason, P.J. (2009) Essential image processing and GIS for remote sensing Wiley-Blackwell, Singapore.

Marcus, W.A. (2002) Mapping of stream microhabitats with high spatial resolution hyperspectral imagery. Journal of Geographical Systems 4: 113-126.

Marcus, W.A., Legleiter, C.J., Aspinall, R.J., Boardman, J.W. and Crabtree, R.L. (2003) High spatial resolution hyperspectral mapping of in-stream habitats, depths, and woody debris in mountain streams. Geomorphology 55: 363-380.

Milan, D.J., Heritage, G.L., Large, A.R.G. and Entwhistle, N.S. (2010) Mapping hydraulic biotopes using terrestrial laser scan data of water surface properties. Earth Surface Processes and Landforms 35: 918-931.

Moir, H.J. and Pasternack, G.B. (2008) Relationships between mesoscale morphological units, stream hydraulics and Chinook salmon (Oncorhynchus tshawytscha) spawning habitat on the Lower Yuba River, California. Geomorphology 100: 527-548.

Montgomery, D.R. and Buffington, J.M. (1997) Channel-reach morphology in mountain drainage basins. Geological Society of America Bulletin 109 (5): 596-611.

Newson, M.D., Harper, D.M., Padmore, C.L., Kemp, J.L. and Vogel, B. (1998) A costeffective approach for linking habitats, flow types and species requirements. Aquatic Conservation: Marine and Freshwater Ecosystems 8: 431-446.

Newson, M.D. and Newson, C.L. (2000) Geomorphology, ecology and river channel habitat: mesoscale approaches to basin-scale challenges. Progress in Physical Geography 24 (2): 195217.

Padmore, C.L. (1998) The role of physical biotopes in determining the conservation status and flow requirements of British rivers. Aquatic Ecosystem Health and Management 1: 2535.

Raven, P.J., Fox, P., Everard, M., Holmes, N.T.H. and Dawson, F.H. (1997) 'River habitat survey: a new system for classifying rivers according to their habitat quality' In Boon, P.J. and Howell, D.L. (Eds) Freshwater quality: Defining the undefinable Edinburgh HMSO p.215-234.

Reid, M.A. and Thoms, M.C. (2008) Surface flow types, near-bed hydraulics and the distribution of stream macroinvertebrates. Biogeosciences 5: 1043-1055.

Reid, M.A. and Thoms, M.C. (2009) Mapping stream surface flow types by balloon: an inexpensive high resolution remote sensing solution to rapid assessment of stream habitat heterogeneity? In IAHS Publication 328, Proceedings of JS.1, Joint IAHS-IAH Convention, Hyderabad, India, September 2009. 
Rivas Casado, M., Ballesteros Gonzalez, R., Kriechbaumer, T. and Veal, A. (2015) Automated identification of river hydromorphological features using UAV high resolution aerial imagery. Sensors 15: 27969-27989

Rychov, I., Brasington, J. and Vericat, D. (2012) Computational and methodological aspects of terrestrial surface analysis based on point clouds. Computers and Geosciences 42: 64-70.

Sieberth, T., Wackrow, R. and Chandler, J.H. (2015) UAV image blur - it's influence and ways to correct it. The International Archives of the Photogrammetry, Remote Sensing and Spatial Information Sciences, Vol. XL-1/W4. International Conference on UAVs in Geomatics, 30 August-2 September, Toronto, Canada.

Tamminga, A., Hugenholtz, C., Eaton, B. and Lapointe, M. (2015) Hyperspatial remote sensing of channel reach morphology and hydraulic fish habitat using an unmanned aerial vehicle (UAV): A first assessment in the context of river research and management. River Research and Applications 31 (3): 379-391.

Tauro, F., Petroselli, A. and Arcangeletti, E. (2015) Assessment of drone-based surface flow observations. Hydrological Processes doi: 10.1002/hyp.10698

Tunnicliffe, J., Fuller, I., Eaton, B., Peacock, D. and Marden, M. (2016) Reconstructing the sediment dynamics of an overloaded gravel bed river, East Cape. Paper 26063 in, Webb, J.A., Costelloe, J.F., Casas-Mulet, R., Lyon, J.P. and Stewardson, M.J. (eds) Proceedings of the $11^{\text {th }}$ International Symposium on Ecohydraulics. Melbourne, Australia, 7-12 February 2016. The University of Melbourne.

Wadeson, R.A. (1994) A geomorphological approach to the identification and classification of instream flow environments. South African Journal of Aquatic Science 20 (1/2): 38-61.

Wadeson, R.A. and Rowntree, K.M. (1998) Application of the hydraulic biotope concept to classification of instream habitats. Aquatic Ecosystem Health and Management 1: 143-157.

Wallis, C., Maddock, I., Visser, F. and Acreman, M. (2012) A framework for evaluating the spatial configuration and temporal dynamics of hydraulic patches. River Research and Applications 28 (5): 585-593.

Westaway, R.M., Lane, S.N. and Hicks, D.M. (2000) The development of an automated correction procedure for digital photogrammetry for the study of wide, shallow, gravel-bed rivers. Earth Surface Processes and Landforms 25: 209-226.

Winterbottom, S.J. and Gilvear, D.J. (1997) Quantification of channel bed morphology in gravel-bed rivers using airborne multispectral imagery and aerial photography. Regulated Rivers: Research and Management 13: 489-499.

Woodget, A.S., Carbonneau, P.E., Visser, F. and Maddock, I.P. (2015) Quantifying submerged fluvial topography using hyperspatial resolution UAS imagery and structure from motion photogrammetry. Earth Surface Processes and Landforms 40 (1): 47-64.

Woodget, A.S., Visser, F., Maddock, I.P., Carbonneau, P. and Austrums, R. (2016) Quantifying fluvial substrate size using hyperspatial resolution UAS imagery and SfM- 
photogrammetry. Paper 25979 in, Webb, J.A., Costelloe, J.F., Casas-Mulet, R., Lyon, J.P. and Stewardson, M.J. (eds) Proceedings of the $11^{\text {th }}$ International Symposium on Ecohydraulics. Melbourne, Australia, 7-12 February 2016. The University of Melbourne.

Wright, A., Marcus, W.A. and Aspinall, R. (2000) Evaluation of multispectral, fine scale digital imagery as a tool for mapping stream morphology. Geomorphology 33: 107-120.

Zavadil, E.A., Stewardson, M.J., Turner, M.E. and Ladson, A.R. (2012) An evaluation of surface flow types as a rapid measure of channel morphology for the geomorphic component of river condition assessments. Geomorphology 139-140: 303-312. 
Tables

Table 1. Descriptions of SFTs and associated biotopes (Newson and Newson, 2000; Environment Agency, 2003).

\begin{tabular}{|c|c|c|}
\hline $\begin{array}{c}\text { Surface Flow } \\
\text { Type }\end{array}$ & Description & $\begin{array}{l}\text { Associated } \\
\text { biotope(s) }\end{array}$ \\
\hline Free fall (FF) & $\begin{array}{l}\text { Where vertically-falling water clearly } \\
\text { separates from the 'back-wall' of a distinct } \\
\text { vertical rock face. }\end{array}$ & Waterfall \\
\hline Chute $(\mathrm{CH})$ & $\begin{array}{l}\text { Low, curving flow with substantial water } \\
\text { contact 'hugging' the substrate. }\end{array}$ & Spill or Cascade \\
\hline $\begin{array}{l}\text { Broken standing } \\
\text { waves }(\mathrm{BSW})\end{array}$ & $\begin{array}{l}\text { Water appears to be trying to flow } \\
\text { upstream. A white water tumbling wave } \\
\text { must be present. }\end{array}$ & $\begin{array}{l}\text { Cascade, Rapid or } \\
\text { Riffle }\end{array}$ \\
\hline $\begin{array}{l}\text { Unbroken } \\
\text { standing waves } \\
\text { (USW) }\end{array}$ & $\begin{array}{l}\text { 'Babbling' water with a disturbed 'dragon- } \\
\text { back' surface, which has upstream facing } \\
\text { wavelets that have not broken. }\end{array}$ & Riffle \\
\hline $\begin{array}{l}\text { Chaotic flow } \\
\text { (CF) }\end{array}$ & $\begin{array}{l}\text { A chaotic mixture of several faster flow } \\
\text { types (free fall, chute, broken and unbroken } \\
\text { standing waves) in no organised pattern. }\end{array}$ & \\
\hline Rippled (R) & $\begin{array}{l}\text { Water surface with distinct, symmetrical, } \\
\text { small ripples that are generally only a } \\
\text { centimetre or so high and moving } \\
\text { downstream. }\end{array}$ & Run \\
\hline Upwelling (UP) & $\begin{array}{l}\text { Upwellings are found where strong upward } \\
\text { flow movements disturb the surface, } \\
\text { creating an appearance of bubbling or } \\
\text { boiling water. }\end{array}$ & Boil \\
\hline Smooth (S) & $\begin{array}{l}\text { Laminar flow where movement does not } \\
\text { produce a disturbed surface. }\end{array}$ & Glide \\
\hline $\begin{array}{l}\text { No perceptible } \\
\text { flow (NPF) }\end{array}$ & $\begin{array}{l}\text { In ponded reaches, where it may be } \\
\text { difficult to perceive any surface water } \\
\text { movement. }\end{array}$ & $\begin{array}{l}\text { Pool or Marginal } \\
\text { Deadwater }\end{array}$ \\
\hline
\end{tabular}


Table 2. Metrics used to assess the accuracy of SFT mapping (after Liu and Mason, 2009).

\begin{tabular}{|c|c|}
\hline Accuracy measure & Definition \\
\hline $\begin{array}{l}\text { Overall accuracy } \\
\qquad \alpha=\left(\frac{1}{N}\right) \sum_{i=1}^{m} C_{i i}\end{array}$ & $\begin{array}{l}\text { Percentage representing total number of correct } \\
\text { classifications (indication of the accuracy of the } \\
\text { SFT mapping as a whole). } \\
\mathrm{N}=\text { total number of ground truth observations } \\
\mathrm{C}_{\mathrm{ii}}=\text { total number of correctly classified } \\
\text { observations }\end{array}$ \\
\hline $\begin{array}{l}\text { User's accuracy } \\
\qquad \beta=\frac{C_{i i}}{N r_{i}}\end{array}$ & $\begin{array}{l}\text { Percentage of correctly classified observations } \\
\text { within a single mapped SFT category as a } \\
\text { proportion of the total number of observations } \\
\text { in that category (i.e. the commission errors). } \\
\mathrm{C}_{\mathrm{ii}}=\text { total number of correctly classified } \\
\text { observations in any given SFT category } \\
\mathrm{Nr}_{\mathrm{i}}=\text { total number of observations in a } \\
\text { particular SFT category (as mapped from } \\
\text { bankside/from orthophoto) }\end{array}$ \\
\hline $\begin{array}{l}\text { Kappa co-efficient (or Cohen's k) } \\
\kappa=\frac{\left(N \cdot \sum_{i=1}^{m} C_{i i}\right)-\left(\sum_{i=1}^{m}\left(N r_{i} \cdot N c_{j}\right)\right.}{N^{2}-\left(\left(\sum_{i=1}^{m}\left(N r_{i} \cdot N c_{j}\right)\right)\right.}\end{array}$ & $\begin{array}{l}\text { Statistical measure of the difference between } \\
\text { (a) the observed agreement and (b) chance } \\
\text { agreement. A maximum kappa value of } 1 \\
\text { would suggest that the SFT mapping is } 100 \% \\
\text { better than one resulting purely by chance and a } \\
\text { value of } 0 \text { would suggest it is no better. }\end{array}$ \\
\hline
\end{tabular}


Table 3. Summary of accuracy measures of the traditional bankside SFT mapping (TB) and SFT mapping conducted on the sUAS-SfM imagery (sUAS), by comparison with independent ground truth data. Percentage of ground truth validation points classed as each SFT is given in columns headed GT. Note: this table does not consider BSW and therefore for the May survey the percentage of ground truth validation points does not sum up to $100 \%$.

\begin{tabular}{|c|c|c|c|c|c|c|c|c|c|c|}
\hline \multirow{2}{*}{\multicolumn{2}{|c|}{$\begin{array}{c}\text { Date of Survey } \\
\text { Method }\end{array}$}} & \multicolumn{3}{|c|}{ May } & \multicolumn{3}{|c|}{ June } & \multicolumn{3}{|c|}{ August } \\
\hline & & TB & sUAS & $G T$ & TB & sUAS & $G T$ & TB & sUAS & $G T$ \\
\hline \multicolumn{2}{|c|}{ Overall Accuracy (\%) } & 66 & 75 & $N / a$ & 74 & 56 & $N / a$ & 57 & 48 & $N / a$ \\
\hline \multicolumn{2}{|c|}{ Kappa Coefficient } & 0.54 & 0.66 & $N / a$ & 0.59 & 0.40 & $N / a$ & 0.30 & 0.27 & $N / a$ \\
\hline \multirow{5}{*}{$\begin{array}{c}\text { User's } \\
\text { accuracies } \\
(\%) / \\
\text { Percentage of } \\
\text { ground truth } \\
\text { validation } \\
\text { points }\end{array}$} & Smooth & 71.0 & 85.7 & $28 \%$ & 66.7 & 44.0 & $23 \%$ & 64.7 & 48.5 & $31 \%$ \\
\hline & USW & 79.4 & 83.3 & $34 \%$ & 85.7 & 76.5 & $39 \%$ & 58.3 & 73.3 & $34 \%$ \\
\hline & Rippled & 50.0 & 58.3 & $25 \%$ & 61.1 & 33.3 & $23 \%$ & 37.5 & 0.0 & $21 \%$ \\
\hline & NPF & 66.7 & 80.0 & $9 \%$ & 71.4 & 100.0 & $9 \%$ & 100.0 & N/a* & $7 \%$ \\
\hline & Upwelling & 28.6 & 75.0 & $3 \%$ & 100.0 & 100.0 & $6 \%$ & 0.0 & 33.3 & $7 \%$ \\
\hline
\end{tabular}


Table 4. ANOSIM test results.

Please refer to Table 1 for SFT abbreviations. *Denotes results which are statistically significant at the $\alpha=0.05$ level. Pair-wise comparisons comprising BSW are not provided for Test B for the May 2013 data because the SfM process failed to produce a reliable refractioncorrected water depth value in the area of BSW. Furthermore, this SFT was not recorded by the ground truth survey or the sUAS mapping during the June or August campaigns. Pairs shown in bold text are referred to in the main text as most separable.

\begin{tabular}{|c|c|c|c|c|c|c|c|}
\hline & \multirow{2}{*}{$\begin{array}{l}\text { ANOSIM } \\
\text { Results }\end{array}$} & \multicolumn{3}{|c|}{ Test A } & \multicolumn{3}{|c|}{ Test B } \\
\hline & & May & June & Aug & May & June & Aug \\
\hline \multicolumn{2}{|c|}{ Global R } & $0.279 *$ & $0.318^{*}$ & $0.197 *$ & $0.183^{*}$ & $0.221 *$ & $0.184 *$ \\
\hline \multirow{15}{*}{ 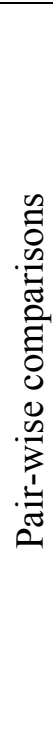 } & S, USW & $0.249 *$ & $0.271^{*}$ & $0.093 *$ & $0.19 *$ & 0.099 & $0.145^{*}$ \\
\hline & $\mathrm{S}, \mathrm{R}$ & $0.114 *$ & $0.204 *$ & -0.045 & $0.101 *$ & $0.220 *$ & 0.016 \\
\hline & $\mathrm{S}, \mathrm{NPF}$ & $0.428 *$ & 0.066 & $0.591 *$ & $0.261^{*}$ & 0.288 & 0.249 \\
\hline & $\mathbf{S}, \mathbf{U P}$ & $0.790 *$ & $0.728^{*}$ & $0.701 *$ & $0.444^{*}$ & $0.962 *$ & 0.287 \\
\hline & USW, R & 0.051 & $0.198 *$ & -0.004 & 0.039 & $0.196^{*}$ & $0.212 *$ \\
\hline & USW, NPF & $0.661 *$ & $0.516^{*}$ & $0.712 *$ & $0.395^{*}$ & -0.189 & $0.627 *$ \\
\hline & USW, UP & $0.776 *$ & $0.746^{*}$ & $0.687 *$ & $0.730 *$ & $0.565^{*}$ & $0.373 *$ \\
\hline & $\mathrm{R}, \mathrm{NPF}$ & $0.406^{*}$ & $0.335^{*}$ & $0.676^{*}$ & $0.191^{*}$ & -0.083 & 0.017 \\
\hline & $\mathrm{R}, \mathrm{UP}$ & $0.564^{*}$ & $0.472 *$ & $0.864 *$ & $0.365^{*}$ & $0.504 *$ & 0.054 \\
\hline & NPF, UP & 0.174 & 0.259 & 0.556 & -0.196 & $0.944 *$ & -0.185 \\
\hline & NPF, BSW & 0.982 & $\mathrm{n} / \mathrm{a}$ & $\mathrm{n} / \mathrm{a}$ & $\mathrm{n} / \mathrm{a}$ & $\mathrm{n} / \mathrm{a}$ & $\mathrm{n} / \mathrm{a}$ \\
\hline & $\mathrm{R}, \mathrm{BSW}$ & $0.932 *$ & $\mathrm{n} / \mathrm{a}$ & $\mathrm{n} / \mathrm{a}$ & $\mathrm{n} / \mathrm{a}$ & $\mathrm{n} / \mathrm{a}$ & $\mathrm{n} / \mathrm{a}$ \\
\hline & USW, BSW & $0.881 *$ & $\mathrm{n} / \mathrm{a}$ & $\mathrm{n} / \mathrm{a}$ & $\mathrm{n} / \mathrm{a}$ & $\mathrm{n} / \mathrm{a}$ & $\mathrm{n} / \mathrm{a}$ \\
\hline & S, BSW & $0.999 *$ & $\mathrm{n} / \mathrm{a}$ & $\mathrm{n} / \mathrm{a}$ & $\mathrm{n} / \mathrm{a}$ & $\mathrm{n} / \mathrm{a}$ & $\mathrm{n} / \mathrm{a}$ \\
\hline & BSW, UP & 0.556 & $\mathrm{n} / \mathrm{a}$ & $\mathrm{n} / \mathrm{a}$ & $\mathrm{n} / \mathrm{a}$ & $\mathrm{n} / \mathrm{a}$ & $\mathrm{n} / \mathrm{a}$ \\
\hline
\end{tabular}



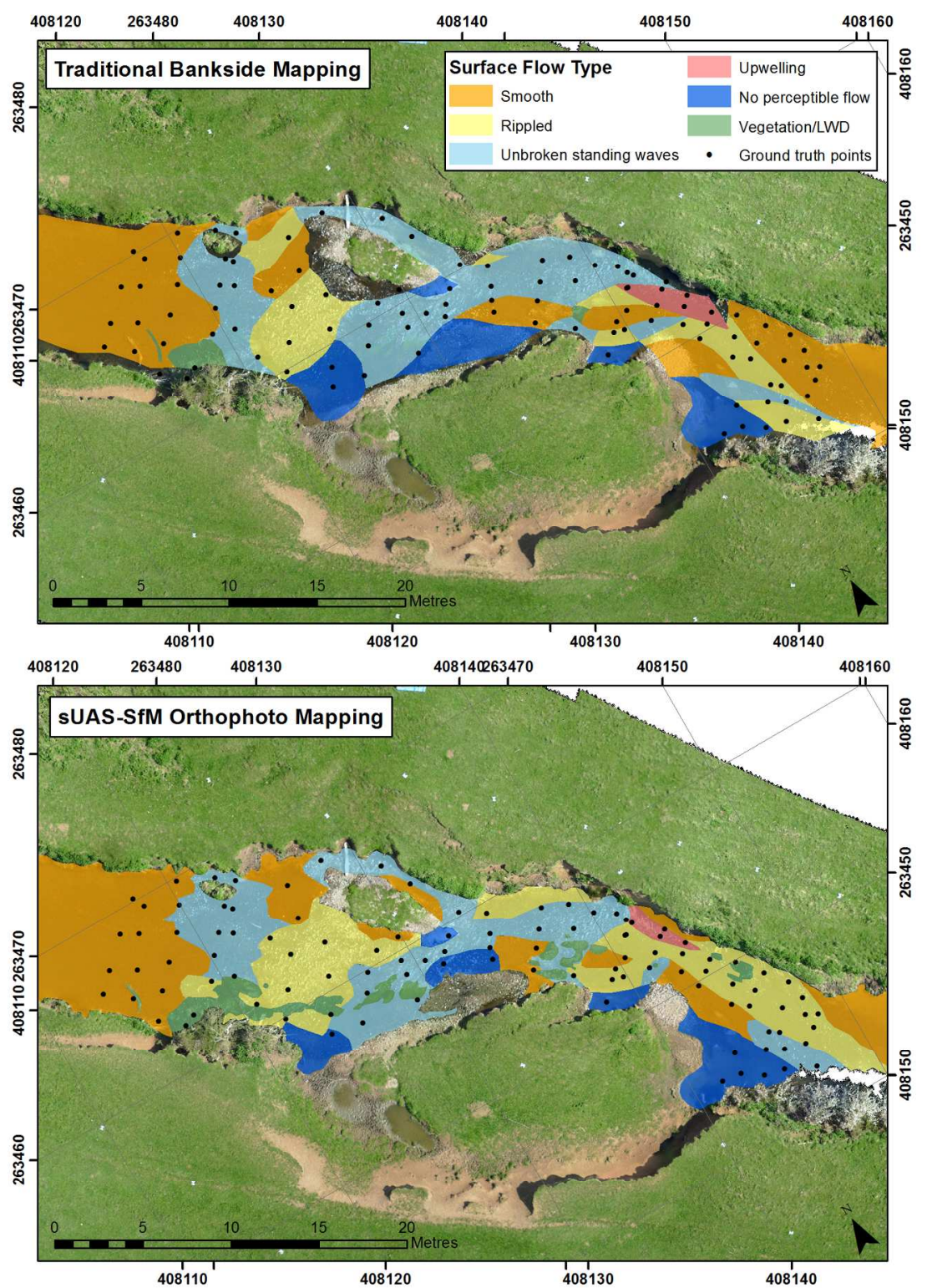

Figure 1. SFT mapping conducted visually from the bankside (top) and from the sUAS-SfM orthophoto (bottom) for the River Arrow May 2013 survey. LWD denotes areas of large woody debris. This figure is available in colour online. $210 \times 297 \mathrm{~mm}(200 \times 200 \mathrm{DPI})$ 


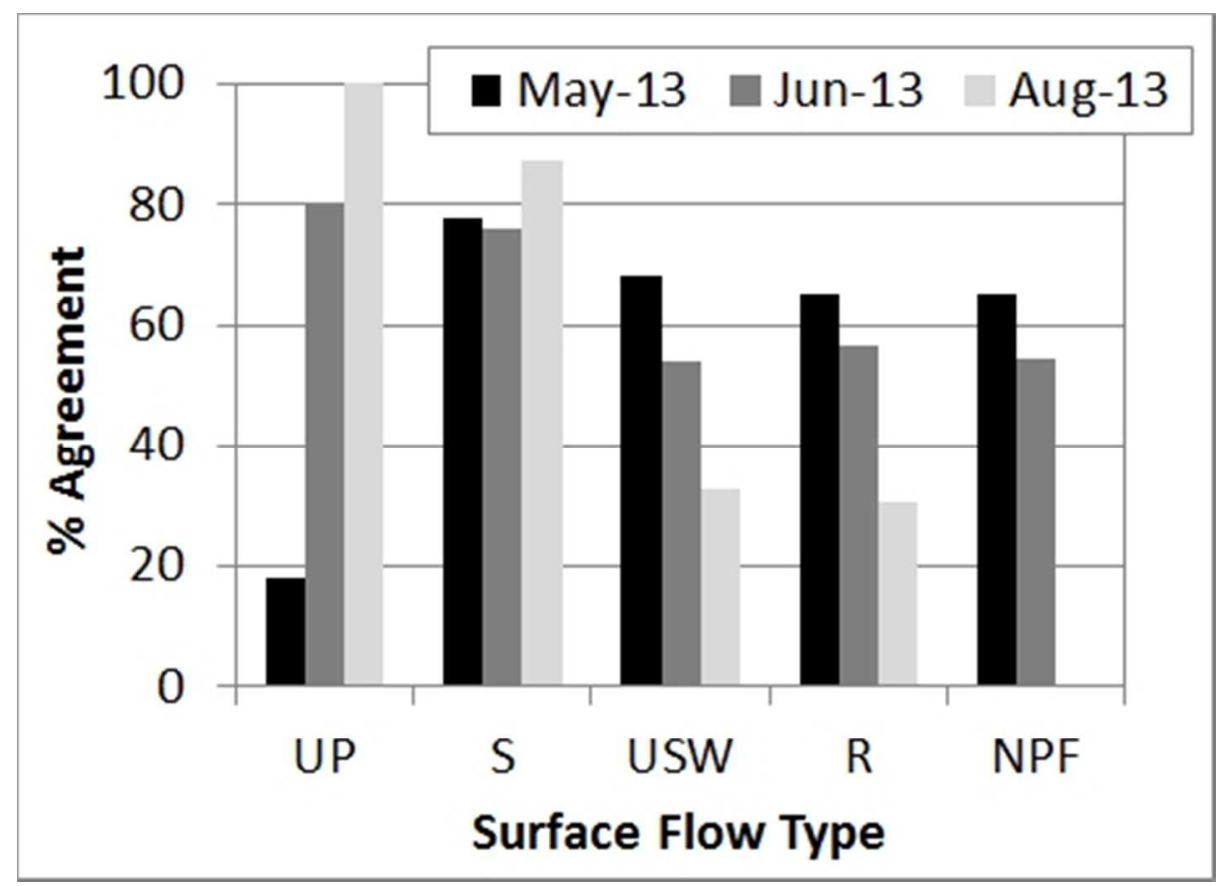

Figure 2. Level of agreement (\%) between traditional bankside and sUAS-SfM mapped SFTs, bu survey and SFT. 

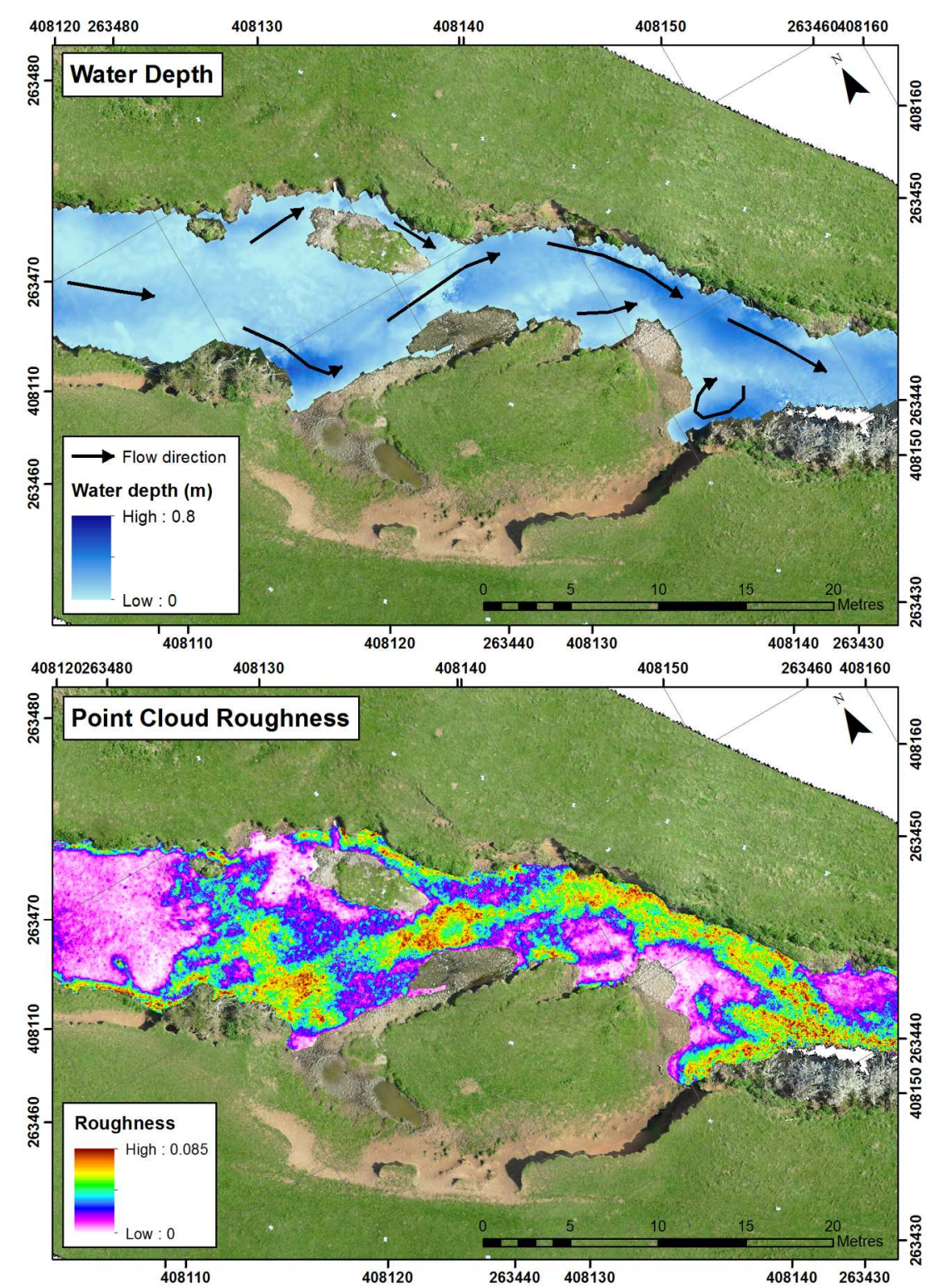

Figure 3. Spatially continuous water depth (top) and point cloud roughness data (bottom), derived from the sUAS-SfM process for the River Arrow May 2013 survey. This figure is available in colour online. $210 \times 297 \mathrm{~mm}(200 \times 200 \mathrm{DPI})$ 


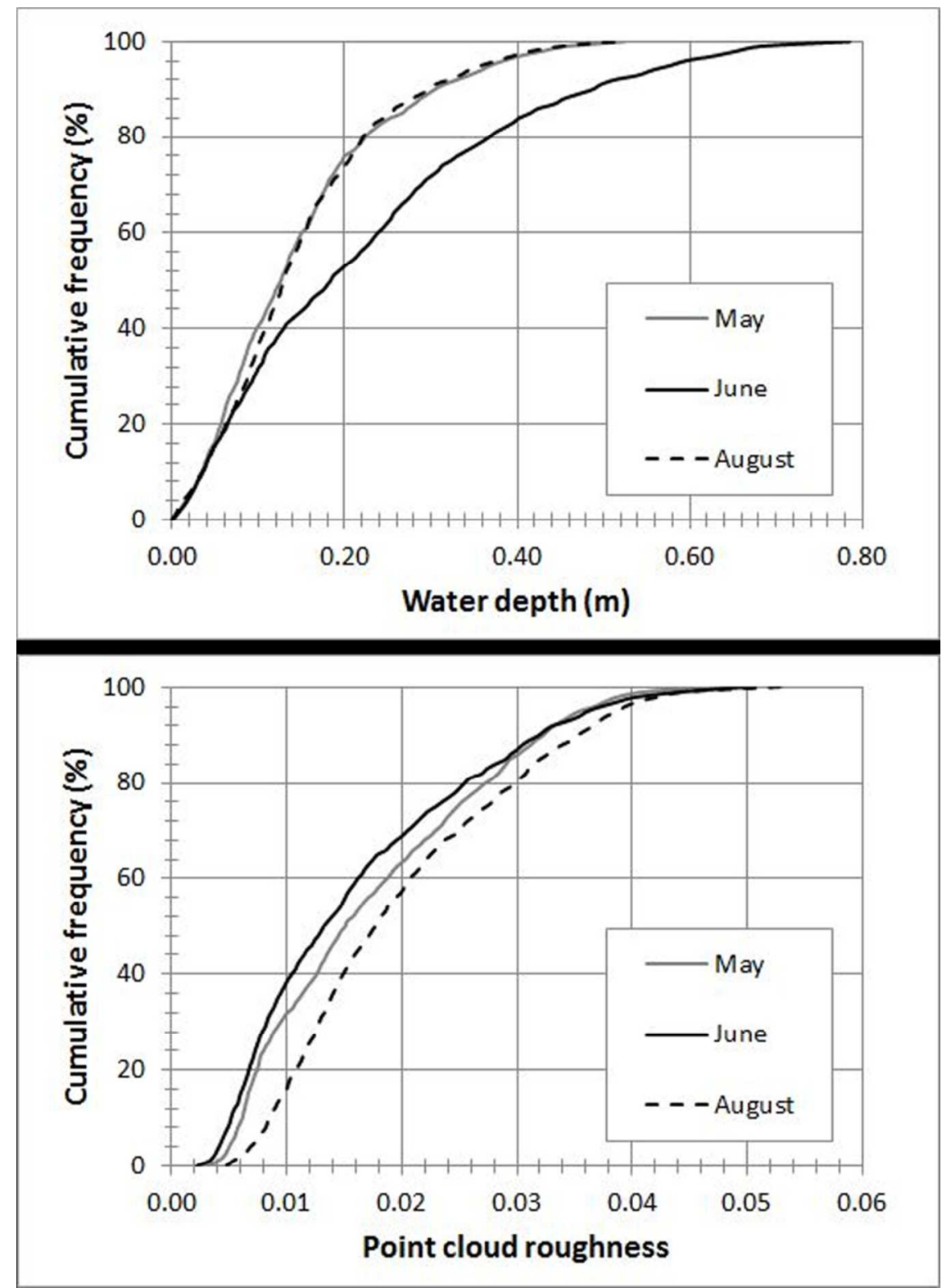

Figure 4. Cumulative frequency distributions of water depth and point cloud roughness for May, June and August surveys. $137 \times 190 \mathrm{~mm}(150 \times 150 \mathrm{DPI})$ 
Figure 5. Regression of point cloud roughness percentiles against RC water depth percentiles by survey date ( $n=101, p<0.01$ for all datasets). Inset table: Descriptive statistics by survey date. 